\title{
The Construction Mode of First-class Courses of Classroom Teaching under the Background of MOOC in Local Colleges
}

\author{
Weigang Li, Yuzhu Zhu*, Xiaojun Ma, Ning Wang and Liling Zhu \\ School of Mechanical Engineering \\ Jiamusi University \\ Jiamusi, Heilongjiang 154007, China \\ *zyz@jmsu.edu.cn
}

\begin{abstract}
Under the impact of information tide, on-line education, with the representative of MOOC, has brought national higher education with unprecedented impact and challenge, and local colleges have also experienced new opportunities and selections. This paper explored the "first-class course" mode based on MOOC in local colleges from the aspect of their pushing the value orientation, operation system and implementation strategy.
\end{abstract}

Keywords-local colleges; MOOC; classroom teaching; implementation strategy; "first-class course"

\section{INTRODUCTION}

The report of the 19th National Congress clearly put forward that we should achieve the connotative development of higher education, deepen the reform in talent training mode, and teaching content and methods. In the Action Plan 2.0 of Education Information issued by the Ministry of Education in April, 2018, it stressed that the development goal of basically realizing "three all, two improving and one big" by 2022 . Specifically, teaching application should cover all teachers, learning application covering all right-age students, and digital campus construction covering the whole school; the level of information application and the information quality of teachers and students should be improved; and the big platform of "Internet plus education" should be established. The specialized resource of education will be changed to big resource, and the information technical application ability of teachers and students should be changed to improving their information quality, and the integrated application should change towards innovative development. We should make efforts to establish the new mode for talent training under the circumstance of "Internet plus", the new mode for education service based on Internet, and the new mode for education management in the era of information.

The development of on-line education with the representative of MOOC has brought local colleges with new opportunities to solve teaching problems, deepen teaching reform and improve teaching quality. At first, the teaching form and organization method of MOOC can make college classroom more oriented with research. A new teaching mode

Fund project: Higher education teaching reform project in Heilongjiang province: The Research on Promoting the Classroom Teaching Mode Reform in Local Colleges under the Background of MOOC() has been created, an integration of on-line videos, off-line tutoring, on-line homework and tests. Meanwhile, MOOC emphasizes interactivity and participation, and it can help improve students' ability of independent learning and innovation. More importantly, the sharing and open system of MOOC could break through the boundaries among colleges, greatly relieve the lack of high-quality teaching resource in local colleges, and promote the popularization and fairness of education.

The appearance of MOOC has given students a kind of learning mode without the limit of time and space, which is benefit to training their independent learning and innovation. In addition, it has helped colleges realize another teaching mode in the era of information, and brought new reform thought for optimizing traditional classroom teaching and improving teaching quality. Therefore, based on the opportunities and challenges brought by MOOC, this paper made certain investigation and analysis with classroom teaching reform in local colleges under the background of MOOC, and it explored the classroom teaching mode reform of first-class course in local colleges from the aspect of optimizing college classroom teaching and improving the effectiveness of classroom teaching.

\section{The VAlue Orientation of Pushing MOOC IN LOCAL COLLEGES}

In terms of the mission of colleges in the new era, the concept of pushing MOOC is respecting individual difference. When learners study various excellent courses throughout the world, the platform can make individualized resource pushing based on the characteristics of learners and provide service for students' individualized learning. The popularization of MOOC can get discipline advantages in all colleges together to construct a learning society in which all people can learn at any place at all times, at the same time of providing high-quality education service for the whole society, and maximally giving full play to the use efficiency and scale profits of education resource. MOOC can truly reduce the threshold and cost of higher education, and push the sharing of high-quality education resource around the world. Thus, there is a chance to change the unequal fairness, which has troubled human beings for a long time, and narrow the education gap among different countries and regions. We uphold the idea of strengthening the 
country by education, people being oriented, pursuing excellent teaching, and contributing Chinese development plan for global higher education. So the promotion and application of MOOC is a valuable exploration and try of performing the mission of colleges in the new era.

\section{The Operation SySTEM OF PUSHING MOOC IN LOCAL COLLEGES}

At present, the main operation system of pushing the application of MOOC in domestic colleges is being oriented with government and colleges, as well as the cooperation between colleges, colleges and enterprises, and various cooperating partners. Local colleges can select the operation system of MOOC based on their own specific conditions so as to promote the construction and teaching reform of MOOC. Currently, our MOOC education is still in the exploration, so faced with the imbalanced arrangement of teaching resource among various regions and colleges, it is necessary to invite enterprises to participate in, seek joint development, and motivates the function of the market in arranging the highquality education resource. Enterprises, colleges and research centers should be combined to push the transformation of research result. Local colleges are supposed to positively cooperate with local enterprises and higher colleges to explore diversified innovative teaching mode of MOOC, and actively mobilize social capital to participate in the construction of MOOC.

In the process, local colleges should pay attention to both selective introduction and selective output. Selective introduction means that they should, based on their own reform needs, introduce MOOC courses of other colleges, regions or countries, or cooperate with the platform of MOOC. Selective output means that they can selectively construct their own MOOC course based on their teachers and teaching conditions, or construct the specialized MOOC platform within their colleges, or cooperate with other colleges. Meanwhile, they should focus on the rational arrangement of resources. The selected courses should match current course system and development demands of teaching, which can help formulate unified standard for MOOC design and development, unified standard for platform technology within the industry, and strengthen the quality supervision and management of MOOC construction. The development and transformation of local colleges can be promoted under the background of MOOC.

\section{The IMPLEMENTATION STRATEGY OF PUSHING MOOC IN LOCAL COLLEGES}

\section{A. Implement various training and multi-channel communication, improve the understanding, and strengthen the responsibility and sense of crisis in teaching reform}

The first one is to carry out the enlightening training with managers due to their insufficient understanding. From the current construction of MOOC in local colleges, the significant premise is that leaders pay enough attention to the construction and all-level teaching managers participate in the construction. Currently, there are still many college managers not realizing the significance of on-line education to college teaching reform, so it is necessary to carry out multi-side communication, discussion and training, and support the teaching reform driven by on-line education on the policy from the macro-strategy. The second one is that grass-roots educational administrators are mainly in charge of the construction and operation of MOOC, so their deep understanding with the teaching characteristics, modes and application of MOOC can provide important support for pushing teaching reform. The third is that teachers' teaching design and teaching service training are the quality guarantee of MOOC. The core content of MOOC construction and teaching reform includes teachers' teaching concept, technological methods, content design, resources and procedures. So establishing the training system for teachers and implement comprehensive teaching training can guarantee the teaching quality of MOOC, and it is a significant method to push the reform of physical classroom teaching. The fourth is that on-line learning has become a new choice for local college students. However, their concepts, methods, technologies and abilities about on-line learning need the guidance, so it is a must for pushing forward the teaching reform to carry out related learning groups and train their learning abilities. Finally, the professional reports and workshops can be well used to clarify the new concepts, technologies and opportunities of teaching to accelerate the construction of MOOC and the continuing teaching reform.

\section{B. Strengthening the policy and system innovation of new technology in teaching area and make the reformers more active}

Technological innovation has pushed the formation and development of MOOC course, and it will be a driver for the future development of MOOC. With the construction and application of on-line courses with the representative of MOOC, related policies and systems should be upgraded and established like the checking method to teachers' teaching hours and the hours and points of MOOC, the limit and standard of on-line teaching service, the assessment method to MOOC, and the evaluation method to students' grades. At the same time, new working amount and problems should be taken into consideration. So it is necessary to issue corresponding encouraging measures, and encourage related teachers to positively participate in the research and set up the models for others.

\section{Increasing the input to promote the constant development of management and technology and accept the challenges of information and intelligent technology to teach}

The teaching reform driven by MOOC is still in the initial stage, and there are too many new problems needing the research, input, and corresponding organizations and constitutions, from teaching design and content to teaching mode, from teaching skills and resources to teaching assessment, from teaching interactivity and effect to teaching experience, from teaching management and operation to mutual credit recognition, from on-line assessment, and teachers' self- and mutual assessment to professional assessment, from the platform function and bug to platform improving, and from individual teacher and group to the 
application popularization. For example, the MOOC office established in Shenzhen University and the MOOC research institutes in Shanghai Jiaotong University are dedicated to the related research and pushing. Recent years, intelligence technology has been integrated with teaching, and there have been on-line robot assistants in America. The era in which AI can replace teachers is coming. Paying attention to and strengthening the application of intelligent technology in teaching is also the advanced project of deepening teaching reform.

\section{Creating exquisite MOOC, foster the demonstration, promotion and application, and satisfy the demand of education consumption upgrading}

The wide application of Internet and information technology has brought students with more pleasant experience and sense of value in knowledge learning. While high-quality MOOC can integrate knowledge, ability, experience and value, which is still in the stage of brand demonstration. But it has been possible to create teaching stars along with the large-scale construction and sharing application of on-line courses, such as Professor Wang Qiong of Peking University, Professor Yu Xinjie of Tsinghua University, Professor Weng Kai of Zhejiang Univeristy, Professor Zhan Dechen of Harerbin Institute of Technology, and Professor Fei Yuenong of Shenzhen University, all of whom are outstanding MOOC teaching stars in the construction of MOOC. They deeply research and carefully construct their own MOOC, and they never stop improving and exploring the thoughts, methods or application of teaching reform. Thanks to their demonstration, lots of teachers are attracted to participate in the construction of MOOC and the practice of integrating new technology and teaching reform.

\section{E. Accelerating the big data construction of on-line course teaching and provide the basis for teaching reform decisions}

Big data has been integrated with various fields and become the important support and methods for their innovation, while the big data research and digging of teaching is just on the beginning. Along with the large-scale construction and application in local colleges, establishing the system of teaching big data and analyzing and researching teaching data from the aspect of teachers' teaching and students' learning can provide scientific basis for the decision of teaching reform and development. The digging of big data can more accurately master students' learning condition, and make corresponding adjustment with learning methods based on students' learning difficulties. Such a self-adapting learning method is gradually becoming the mainstream way of future learning. It is expected that on-line education can provide significant data for teaching reform in data collection, analysis and digging.

\section{THE “FIRST-CLASS COURSE” MODE BASED ON MOOC IN} LOCAL COLLEGES

\section{A. Establishing the "first-class course" mode in local colleges}

It is necessary to connect with the document requirement of the Notice on the Implementation of the Spirit of the National Conference on National Undergraduate Education in the New Era issued by the Ministry of Education, and further strengthen college education and teaching order. In addition, course construction should be strengthened to eliminate those "poor course" featuring "low-ranking, old and not careful”, instead, we should create the "first-class course" featuring "highranking, innovative and challenging”. The selection standard for first-class course should be formulated, and Attention must be paid to creating on-line and off-line first-class course.

As for the related modes, there are five kinds of modes which is featuring clear objective and orientation, and there is a "mode of Sichuan University" to be referred to. The construction of local college course has prominent problems and it needs continuing improvement. Taking the example of Jiamusi University, its mode is to highlight the "first-class course" of social practice, which is corresponding with college principles and orientation. It regards the first demonstration college brands of innovation and entrepreneurship education reform in Heilongjiang as the support, the second class as the carrier, and the ideological guidance, art and social practice, innovation and entrepreneurship education, various innovation and entrepreneurship activities and competitions as the manifestation. All of the policy, organization, mechanism, assessment and fees have the possibility of previous accumulation and prior development.

\section{B. Strengthening the construction of on-line open course above the provincial level}

We should strengthen the construction of exquisite open courses, resource sharing courses and network courses, enrich the on-line course resources, and create a batch of high-quality course groups. In addition, we should implement the hundredcourse (the second period) construction, establish the related access system, and strengthen the central construction which requires that two professional core courses at least in each major should be included into the course central website. We should launch the reform of course assessment methods, and insist the integration of teaching methods, students' learning methods, and teachers' evaluation methods to comprehensively strengthen course evaluation. What's more, we should positively participate in the construction of college teaching cooperation around the country, explore the joint sharing system of high-quality resources, and promote the mutual employment among teachers, mutual selection among courses and mutual recognition of credits.

\section{Strengthening the construction of on-line courses}

Therefore, we should strengthen the construction of on-line course, advance the establishment of the third on-line course, make efforts to add another ten courses in 2019, and make enough preparation for the 2019 on-line exquisite course at the national level and provincial level. 
D. Comprehensively improve the construction of course and professional ideology and politics

Every teacher is supposed to strengthen the awareness of establishing good morality, organically integrate ideological and political education with every course, construct a batch of exquisite professional courses with obvious teaching effect, create related demonstration classrooms and excellent teachers, and promote the close connection of professional course teaching and ideological and political course teaching, as well as the training form of keeping in the same direction.

It is in the stage of reforming methods and transforming teaching supply methods. MOOC, on the open on-line platform, is the opportunity for the development of higher education. The managers and course constructors of higher education should seize this opportunity to positively learn from the successful experience of other countries, take advantage of MOOC and avoid its bad effects to truly promote the teaching system reform of higher education.

\section{REFERENCES}

[1] Wang Kexin. Discussion on the classroom teaching reform strategies in local colleges under the background of MOOC [J]. Technology Wind,2018(22):29.

[2] Wang Xiaoyu, Xie Hui and Guo Lei. Discussion on the classroom teaching reform strategies in local colleges under the background of MOOC [J]. Journal of Guangxi College of education, 2018(03):162-164.

[3] Wang Rui and Yang Shuchen. Classroom teaching reform and practice of Basic Program Design in the context of transformation and development of local colleges [J]. Journal of Jilin Engineering Normal University, 2017, 33(01):86-87.

[4] Gong Yuanyuan. The application and research of "O2O teaching mode" in the ideological and political course of local colleges [D]. Guangxi Normal University, 2016.

[5] Wang Han. Design of classroom teaching mode in local colleges under the background of MOOC [D]. Qinghai Normal University, 2016.

[6] Xiang Wenjiang, Tang Jie and Zhou Ping. Research on the teaching management reform in local colleges under the background of MOOC [J]. China Modern Educational Equipment, 2015(13):22-25. 